\title{
Accounting for Trust: A Conceptual Model for the Determinants of Trust in the Australian Public Accountant - SME Client Relationship
}

\author{
Michael Cherry ${ }^{1}$
}

\begin{abstract}
This paper investigates trust as it relates to the relationship between Australia's public accountants and their SME clients. It describes the contribution of the accountancy profession to the SME market, as well as the key challenges faced by accountants and their SME clients. Following the review of prior scholarly studies, a working definition of trust as it relates to this important relationship is also developed and presented. A further consequence of prior academic work is the development of a comprehensive conceptual model to describe the determinants of trust in the Australian public accountant - SME client relationship, which requires testing via empirical studies.
\end{abstract}

JEL Classification: M40

Keywords: Trust, public practice accountant, SME, B2B, compliance services vs noncompliance services, conformance vs performance services, third tier and beyond, expectations gap.

\footnotetext{
${ }^{1}$ Charles Sturt University, Australia. Doctoral student. mcherry@ raffrey.com.au
} 


\section{Introduction}

This paper investigates trust in the important relationship between Australia's public practice accountants and their small and medium-sized enterprise (SME) clients. The oft-quoted adage of the accountant as their SME clients' trusted partner (Bennett \& Robson, 2005; Berry, Sweeting \& Goto, 2006; Jay \& Schaper, 2003; Kirby \& King, 1997; Leung, Raar \& Tangey, 2008) requires further attention, particularly in the Australian context. Trust needs to be more clearly defined and its antecedents understood for the accounting profession to meet current and projected challenges. This paper justifies the need for further research into this relationship and presents a new conceptual model to describe the determinants of trust in this relationship, a definition for this trust and further clarity on the important role of the public accountant. In particular, the proposed conceptual model seeks to better describe the value provided by public accountants to their SME clients and identify the determinants, or antecedents, of trust in this relationship.

Initially, this paper describes the contribution of public accountants to the broader economy and to their SME clients in particular, as well as that of the SME sector itself. A review of prior literature, particularly the work by Saunders, Wu, Li, and Weisfeld (2004) and Blackburn, Carey, and Tanewski (2010) identifies that the area of trust remains under-researched for business to business relationships generally and for Australian public accountant - SME client relationships specifically. The important issues of conformance-related services and performance-related services and the emergence of an expectations gap is highlighted by various authors (Berry, Sweeting, \& Goto, 2006; Blackburn et al., 2010; Dyer \& Ross, 2007; Kirby \& King, 1997; Leung, Raar, \& Tangey, 2008). An important outcome of this paper is the development of a rigorous working definition of trust as it relates to the Australian public accountant - SME client relationship. From the literature review and theoretical framework (Blackburn et al., 2010; Dyer $\& \mathrm{Chu}, 2011)$ a new conceptual model is also presented to identify the determinants of this trust in the public accountant - SME client relationship. The potential contributions to knowledge, to the three key audiences of; public practice practitioners, SMEs and academics are also presented. The coming section, provided for important context and background, describes Australia's public practice accountancy sector, with particular emphasis on its scale, scope, roles and objectives, the major players, accreditation bodies and key issues faced by the industry. In addition, a similar overview will be provided of Australia's SME sector.

\section{Importance of the Public Practice Accountancy Sector to Australia's SMEs}

\section{Australia's Public Practice Accountancy Sector}

Australia's public practice accountancy sector is estimated to comprise in excess of 30,000 firms, with annual revenue in the vicinity of $\$ 17$ billion (Chia, 2014). Industry concentration is low with the 'Big Four' (Deloitte Touche Tohmatsu/ Deloitte, KPMG, Ernst \& Young/ EY and PricewaterhouseCoopers) representing just under $20 \%$ of the overall marketplace on a revenue basis (Chia, 2014). 'Second Tier' providers (approximately 50 firms) represent a further estimated 17\% of the market (Khadem, 2012). The balance of the sector (Third Tier and Beyond) therefore numbers around 30,000 practices and accounts for approximately $60 \%$ of overall revenue (or $\$ 10$ billion pa) within the market. These practices would indicate that they primarily 
service Australia's small to medium enterprises (SMEs), high net worth individuals and tradespersons. This paper intends to explore the relationship between these Third Tier and Beyond accountancy practices and their SME client base. The global Association of Chartered Certified Accountants (ACCA, 2013) describes the seven key roles provided by public accountants to their SME clients as; general personal advice as mentor or advisor, financing liaison, provision of compliance and governance services, operational support, financial reporting, commercial support and strategic business planning advice.

According to the Australian Accountants Directory, Australia has three officially recognised professional accounting bodies (Australian Accountants Directory, 2014);

- $\quad$ The Institute of Public Accountants (IPA)

- CPA Australia (CPA) \&

- Chartered Accountants Australia and New Zealand (CAANZ)

The objectives of these bodies are summarised below and a working definition for public accountants is distilled for use within the proposed conceptual model. According to IPA (2014b), Dun \& Bradstreet's international definition of 'public accountant is, "Independent Public Accountants perform many functions, including auditing financial statements, designing financial accounting systems, assisting in managerial accounting function, providing managerial advisory services, and tax preparation. The public Accountant may perform services for corporations, partnerships, individuals and other organisations" (IPA, 2014a). CPA Australia defines public accounting services to include the following; accounting, bookkeeping, auditing and assurance, taxation, insolvency and corporate reconstruction, management accounting, financial planning and financial reporting. They also suggest that information technology, management consultancy, business valuations, forensic accounting or company secretarial services are not included in public accounting services, unless provided as part of the initial services listed (CPA-Australia, 2014). The CAANZ definition of a Chartered Accountant (CA) is broader again and highlights how CAs differentiate themselves via; superior analytical thinking, ability to solve complex problems, highly developed communication and technical skills, dedication to completing work to the highest standard, commitment to self-improvement and development, ambition to achieve the best for their clients and a membership of a global collective of bright minds at the pinnacle of their profession (CAANZ, 2013).

All three bodies have a strong focus on the compliance-related duties of their members, for example, preparation of financial reports and taxation services. However, the provision of other consulting-related services is also acknowledged and captured, to the extent that these services relate to the initial public accounting services. That is, an expansion beyond conformance-related activities (for example, statutory taxation matters) to performancerelated activities (business improvement and growth) is also encouraged. This move has also been seen in other markets with the Institute of Chartered Accountants in England and Wales (ICAEW) actively promoting their members as a source of business support, as well as traditional compliance/conformance activities (Berry et al., 2006). 
An overview of the current trends within Australia's public practice accountancy has identified several salient issues or opportunities impacting, or likely to impact, the industry. Khadem (2013) highlights the following trends for Australia's top one hundred public accountants during 2013; growth in tax advisory and business advisory disciplines, staff redundancies across more than one third of firms, revenue drops, industry consolidation to maintain growth, technology and the digital space and the opportunities across Asia. Whilst this article only catches the top end of third tier public practice firms, the issues identified also remain relevant to the third tier and beyond space. The Accounting Professional \& Ethical Standards Board (APESB) speaks to the increasing prevalence of outsourcing of; financial statements, specialist taxation advice, taxation returns, bookkeeping services, data entry and administration in their discussion paper in this area (APESB, 2008). CAANZ and CPA Australia (Noroozi \& Addison, 2008) in their submission to the Australian Taxation Office make mention of cost drivers, labour shortages and a generation of Australian financial professionals who are unwilling to engage in taxation compliance tasks (the Gen Y factor) as the primary drivers of the outsourcing and indeed offshoring (to India and other Asian countries) of tax compliance tasks.

As a result of the above overview of the three recognised professional bodies and their objectives, and the challenges faced by public accountants and their SME clients, the following working definition of accountants is proposed for use with the proposed conceptual model. It acknowledges both conformance-related and performance-related activities and services:

\section{Australia's public accountants provide clients with financial conformance and performance services. Financial conformance services speak to compliance-related activities, whereas financial performance services speak to broader business advisory activities, aimed at business improvement and growth.}

Having highlighted the scope, scale and challenges of Australia's public practice accountancy sector and developed a definition for the accounting offer, it is appropriate to assess the same issues, from the perspective of the SME client.

\section{Australia's SME Sector}

In Australia, SME organisations have been classified by the Australian Bureau of Statistics (ABS) in the following manner (ABS, 2005).

- Small employing businesses - businesses with employment of fewer than 20 persons and includes micro employing businesses (businesses with employment of fewer than 5 persons) \& other employing small businesses (businesses with employment of 5 to fewer than 20 persons).

- Medium employing businesses - businesses with employment of 20 to fewer than 200 persons." (ABS, 2005)

It is estimated that SMEs employ up to $70 \%$ of Australia's workforce and contribute approximately 55\% to economic output (Creighton, 2012). This SME strength and importance is 
similar throughout all economies globally (Culkin \& Smith, 2000). Australia's SMEs are also predominant in important industries such as retailing, services and construction (Wang, Walker, \& Redmond, 2007). The Australian Government's Department of Innovation, Industry, Science and Research (2011) indicates there were approximately 2 million actively trading businesses in Australia at June 2009. Around 96 per cent were small businesses, 4 per cent were medium-sized businesses and less than 1 per cent were large businesses. That is, the population of SMEs in Australia is estimated at just over 2 million. Some of the current challenges faced by these SMEs are described below.

From the accounting industry's standpoint, some of the key challenges facing Australia's SMEs include, access to funding/finance as well as the burdens of regulations and taxation policy (CPA-Australia \& CGA-Canada, 2010). Griffin and Wilkinson identified 'red tape' and regulation generally, availability of finance, levels of market concentration, as well as franchising matters impacting NSW's SMEs (Griffith \& Wilkinson, 2012). The Australian Chamber of Commerce and Industry (ACCI) Small Business Survey of 2014 highlighted the following constraints on small business; business taxes and government charges, insufficient demand, non-wage labour costs, competition, wage costs, competition, federal and state regulations, current levels of debt, insufficient retained earnings and import competition (ACCI, 2014). More broadly, as published by the Australian Institute of Company Directors (AICD), Hutchinson (cited in AICD, 2013) reports the following challenges for Australian Industry in 2014; a rapidly-changing sales environment, increased investment in innovation, superannuation guarantee payments, transfer pricing, corporate governance and probity issues, due diligence in business transactions, cross-border demand increases as well as changes to the Personal Property Securities Act. Public accountants, RSM Bird Cameron, through their longitudinal benchmarking study, thinkBIG 2012, highlighted the following SME matters (RSM Bird Cameron, 2012); impact of the global financial crisis, business outlook, starting new businesses, business planning, business growth, succession planning and business exits, superannuation planning, self-managed superannuation funds, use of external advisors, employment outlook, work/life balance and online presence. There is strong consistency and correlation across many of the key issues identified above. Many are of a financial nature and certainly within the remit of the public accountant as potential areas of advice and service offerings to their SME client base, beyond traditional compliance (or conformance) related tasks.

As identified above, this paper reviewed relevant literature, specific to the relationship between Australia's public accountants and their SME clients to gain insights around the key question, do SMEs believe their public accountant is a trusted advisor and what are the determinants of that trust? Given the trends and issues identified above, it will also seek to assess the extent to which performance-related services (beyond conformance-related services) contribute to this trust. To ensure rigour in this process a review of the various definitions of trust is undertaken, before reviewing trust antecedents and determinants in the broader business environment, before assessing pertinent material relating to public accountants and their SME clients. This will show that the area of trust remains under-researched from both business to business relationships generally (Saunders et al., 2004) and Australian public accountant - SME client relationships specifically (Blackburn et al., 2010). 


\section{Prior Research}

This review of previous literature will initially explore trust and its various definitions and then investigate trust in a broader Business-to-Business (B2B) sense, before focusing in on trust within the professional services sector and then on trust as it relates to the Australian public accountant - SME client specifically. An outcome of this exercise will be the development of a working definition of trust in the Australian public accountant - SME client context. This trust definition will then be utilised as part of the proposed conceptual model for the determinants of such trust in this relationship.

\section{Accounting Trust}

A review of the literature in this area demonstrates the foundation need for trusted advisor status amongst public accountants. Across international borders we see the concept of trust and the value associated with the profession, for example:

- United States of America "For decades, CPAs in public practice have laid a foundation of trust with clients by competently handling confidential financial data and performing core services such as tax preparation." (Ferguson, 2012)

- United Kingdom "Accountants are the most valued professional adviser when it comes to business advice, with a fifth of small businesses believing that their accountant provides them with the most valuable business advice." (Clarke, 2011)

- Australia "Accountants remain the trusted advisers to Australian small business with almost 70 per cent of business owners claiming they would consult their accountant on business decisions." (Olsen, 2010).

The trust term is a relative one, what does it actually mean in absolute terms and what are its determinants? Trust is certainly a complex term, due to the myriad of interactions between the two parties to the relationship, public accountants and their SME clients. The upcoming section seeks to review relevant literature, specific to the relationship between Australia's public accountants and their SME clients to gain insights around the key question, do SMEs believe their public accountant is their most trusted advisor and what are the determinants of that trust? Various authors have developed definitions for trust, which will also be reviewed. From this review, the following paragraphs will also seek to develop a working definition of trust, drawing from different disciplines, before distilling a working definition to be used to as part of the proposed conceptual model.

\section{General Trust Definitions}

Trust definitions were assessed across a range of disciplines (Blomqvist, 1997) and applied to the public accountant - SME client relationship. Blomqvist's (1997) work explored trust in social psychology, philosophy, economics, contract law and ultimately, B2B marketing. This paper is relevant to this discussion as it provides a broad overview of trust, before focusing on trust as it relates to the B2B relationship and specifically the professional services relationship enjoyed between the public accountant and their SME client. Failings in these various trust definitions (Blois, 1999) were also reviewed and discussed. From a social psychology standpoint, trust 
implies allowing oneself to be in a vulnerable position relative to another, whilst having an understanding of the other which inspires trust in their goodwill or intentions. Most of the definitions note the, "reciprocal and self-enforcing nature of trust." (Blomqvist, 1997, p. 272). Blomqvist (1997) also suggests that trust is limited if one believes in the trustworthiness of another, without relying upon it. Additionally, reliance on another party without believing in their trustworthiness perhaps relates more to power and control, rather than trust. Blomqvist (1997) acknowledges that philosophers have written very little on trust. Generally, philosophers emphasise a trusting attitude as being part of life. Reliance, however, is seen from a narrower perspective (separate from trust), where someone might be relied upon for specific tasks. In a similar fashion to philosophers, economists have also not focused on the area of trust. (Blomqvist, 1997, p. 274) suggests, “....perfect information and pure competition between independent and faceless traders, does not involve trust as a central concept, since the competitive market is supposed to control any deception." Those economists who acknowledge trust generally define it as mutual confidence, or as a response to expected future behaviour. Lawyers writing on trust generally focus on it as a complement to the formal contract itself. Interestingly, Blomvqvist (1997) suggests that very few businesspeople enter into significant contracts without the existence of trust between the parties. That is, contracts play an important role setting out the specifics of the agreement, but they do not guarantee that the parties have committed to act as agreed in the contract. Finally, trust in marketing is reviewed by Blomqvist (1997) and draws upon B2B relationship marketing, distribution channels, personal selling, professional-client relationships and market research. Trust is only more recently being explored, especially in the emerging area of relationship marketing, where power and conflict have historically been important to marketing literature. Trusting behaviour is seen as a long-term attitude, with empirical evidence supporting trust in relationships. It is also acknowledged that much more research is required in this area. Blomqvist (1997) provides a summary of the concepts commonly used as synonyms of trust: competence, credibility, confidence, faith, hope, loyalty and reliance. Blomqvist (1997, p. 282) also offers the following as a working definition of thrust for business contexts, which includes both technical capabilities, responsibility and positive intentions, "An actor's expectation of the other party's competence and goodwill."

The work by Blois (1999) also highlights an overall lack of clarity in the conceptualisation of trust across a number of influential studies. Blois (1999) draws the following definitions of trust from academic journals relating to relationship marketing in the business to business (B2B) space:

- Trust is defined as 'an attitude displayed in situations where .... a person is relying on another person, a person is risking something of value, and/or a person is attempting to achieve a desired goal.' (Bialaszewski \& Giallourakis cited in Blois, 1999, pp. 197-198).

- 'Trust has been defined as the belief that a party's word or promise is reliable and that a party will fulfil his/her obligations in an exchange relationship.' (Schurr \& Ozanne cited in Blois, 1999, p. 198).

- '[Mutual trust is] the degree to which the channel member perceives that its relationship with the supplier is based upon mutual trust and thus is willing to accept short-term dislocation because it is confident that such dislocation will balance out in the long run.' (Anderson et al. cited in Blois, 1999, p. 198).

- 'We define trust as one party's belief that its needs will be fulfilled in the future by actions undertaken by another party.' (Anderson \& Weitz cited in Blois, 1999, p. 198). 
- '[Trust is] the firm's belief that another company will perform actions that will result in positive outcomes for the firm, as well as not take unexpected actions that would result in negative outcomes for the firm.' (Anderson \& Narus cited in Blois, 1999, p. 198).

- 'Trust is defined as a willingness to rely on an exchange partner in whom one has confidence.' (Moorman et al., Schurr \& Ozanne, Ganesan cited in Blois, 1999, p. 198).

- 'We conceptualize trust as existing when one party has confidence in an exchange partner's reliability and integrity.' (Morgan \& Hunt cited in Blois, 1999, p. 198).

- 'We define trust as the perceived credibility and the benevolence of a target of trust.' (Doney \& Cannon cited in Blois, 1999, p. 198).

The above definitions, in a business context, continue to reinforce words such as; reliability, confidence, integrity and credibility as the basis for their trust definitions. Whilst a broad consistency in definitions exists, more clarity is required around the definition of trust, how it might be achieved, as well as how it might be measured or quantified in a business environment. Blois (1999) concludes that the reviewed marketing studies fail to take into account the following five issues:

- Trust and Reliance - highlights that trust and reliance, whilst often used interchangeably, are not actually the same. Blois (1999) argues that, "trust involves depending on their goodwill and not just their dependable habits and so trust has an emotive element which becomes apparent when we are let down.

- Blanket Trust - is seldom applied to another party for two reasons. Firstly, we might trust an individual in particular areas of their behaviour, but not in other areas. Secondly, where there is no experience on which to make a judgement, there may be no view of trustworthiness in that area of behaviour.

- Reciprocity - is often implied in some trust definitions. However, there is no reason why this would need to be the case. If one individual trusts another, it does not necessarily follow the other way around.

- Trust and Trustworthiness - are often not distinguished in the literature, as Blois (1999) argues, "even though it is primarily about trustworthiness, and not about trust." Trustworthiness relates to a person's disposition towards honesty. Trusting a person requires us to know of their disposition as well as the circumstances around the task at hand.

- Can Organisations Trust? - Much of what has been written about trust relates at the level of the individual. Some authors have identified the need to extend the model of trust to the group or organisational level (Schoorman, Mayer, \& Davis, 1996). As trust may only be granted by individuals, organisational or inter-organisational trust generally suggests that individuals from one entity trust those from another.

The above definitions will be refined further, into a working definition for the Australian public accountant - SME client relationship, after exploration of trust with broader business and more specific professional services relationships in the coming paragraphs.

\section{Business-to-Business (B2B) Trust}

A review of prior research in the areas of trust within the business marketing, relationship marketing and services marketing environments is beneficial, as these areas complement the role 
of the public accountant from a professional services standpoint. As part of this exercise, useful and relevant B2B empirical studies were reviewed and provided guidance on the development and refinement of a model for future research. It should be noted that the 2004 work by Saunders et al. identified that trust within business to business relationships was under-explored to that point. This lack of clarity in the area of trust and its antecedents is reinforced in the Australian professional services space, and particularly for public accountants, by Blackburn et al. (2010). Most models on trust (Blackburn et al., 2010; Coulter \& Coulter, 2002; Gooderham, Tobiassen, Døving, \& Nordhaug, 2004; Kirby \& King, 1997; Robson \& Bennett, 2000) presented independent variables covering person-related and offer-related characteristics as potential trust antecedents and determinants and trust as a determinant of loyalty and commitment. Based on these findings Figure 1. below has been distilled from the above models of B2B trust and offered to provide an initial, generic B2B model of trust determinants. A starting point, if you will, before being developed and refined further, to describe the proposed conceptual model relating to the Australian public accountant - SME client relationship.

\section{Figure 1. Generic B2B Trust Model}

Developed from the trust models presented by Blackburn et al. (2010), Coulter \& Coulter (2002) Gooderham, Tobiassen, Døving, \& Nordhaug (2004), Kirby \& King (1997) and Robson \& Bennett (2000).

\section{Independent Variables Dependent Variable}

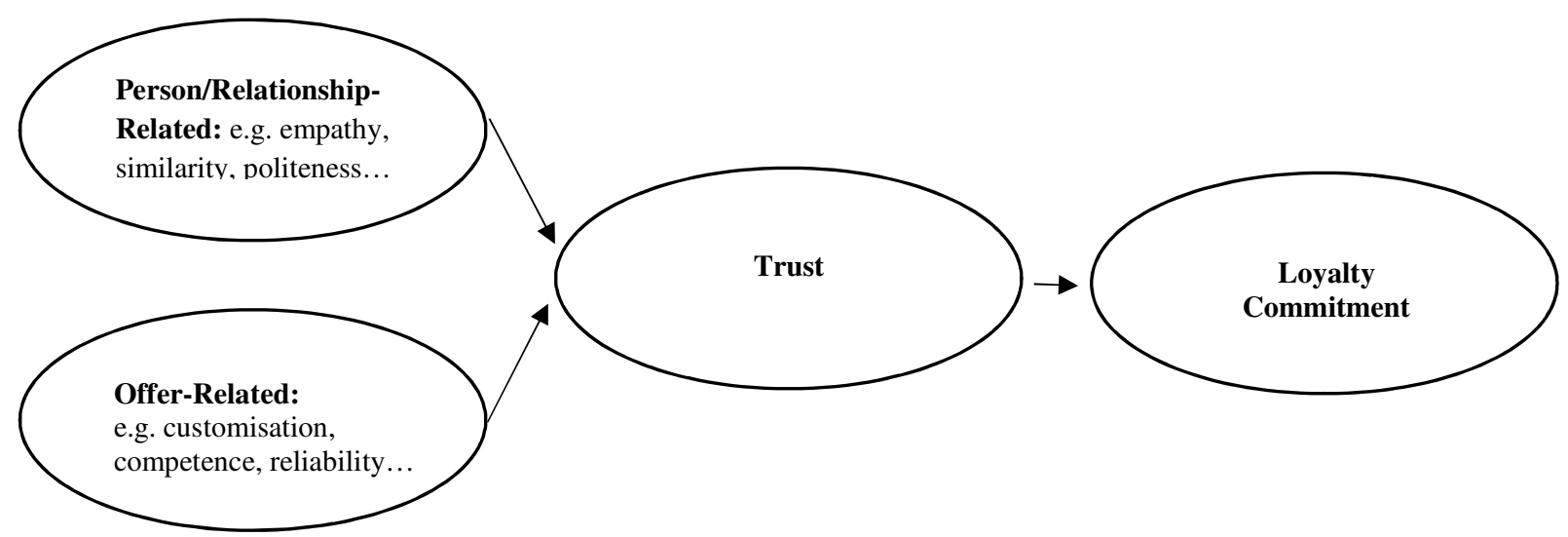

\section{Trust in the Public Accountant - SME Client Relationship}

Whilst some sources cited related to the Australian public accountant - SME relationship, most drew from European experiences (Bennett \& Robson, 2005; Berry et al., 2006; Chumpitaz Caceres \& Paparoidamis, 2007; Gooderham et al., 2004; Kirby \& King, 1997; Lian \& Laing, 2007; Seal \& Vincent-Jones, 1997; Sharif, Kalafatis, \& Samouel, 2005) and North American experiences (Coulter \& Coulter, 2002; L. M. Dyer \& Ross, 2007; Neu, 1991; Rosenbaum, Massiah, \& Jackson Jr, 2006). The need for public accountants as trusted advisors is well understood (Bennett \& Robson, 2005; Berry et al., 2006; DEWRSB, 1996; Jay \& Schaper, 2003; Kirby \& King, 1997; Leung et al., 
2008 ) and they are widely acknowledged as such across Europe, USA and Australia (Clarke, 2011; Ferguson, 2012; Olsen, 2010). What is less well understood are the determinants of trust in the public accountant - SME client relationship. In a similar fashion to the Saunders et al. (2004) observation regarding trust in B2B relationships, Blackburn et al. (2010) also confirm the same for the public accountant - SME client relationship, particularly in relation to Australia.

As mentioned previously, according to Saunders et al. (2004), the issue of trust within business to business relationships is under explored and under researched. Focusing specifically on the nature and antecedents of trust at the level of the public accountant and their SME clients, this lack of research is even more apparent. Various useful and relevant papers cover the public accountant - SME relationship and trust in general, most fail to adequately address the determinants of trust. These papers are reviewed below.

An Australian work, which specifically addresses the role of trust as it relates to the public accountant - SME relationship, is that by Blackburn et al. (2010). Its significance relates to its very specific exploration of the role of trust, relationships and professional ethics in the supply of advice by public accountants to their SME clients, in the Australian context. This work concluded that additional advice was sought by SMEs in their early years, as they face new challenges and build their own competencies. However, not all SMEs use their accountant for such advice. Some SMEs expressed mixed views on the capability of their accountants to provide business advice, yet all accountants suggest they possess such skills. This possibility of an expectations gap is noteworthy and is expressly identified by Kirby \& King (1997) and Blackburn et al. (2014). Most accountants agreed that their existing SME client relationships had been built upon competency, empathy and trust. The Blackburn et al. (2014) work provides some useful anecdotal insights into potential determinants of trust in the relationship between accountants and their clients, which will be discussed in the following paragraphs. A significant implication for accounting practice is the need for accountants to create a pathway for the provision of business advisory services, particularly as business owners do not necessarily seek out their accountants for such work and to do so without diminution of their status as a trusted advisor with empathy for their SME clients. The Blackburn et al. (2010) paper also confirms that scholarly work has primarily investigated trust and competence between larger organisations, whilst such work has been scant and underdeveloped in the SME context. The work by Bennett \& Robson ( 20005 ) across UK advisors and SMEs provides some further insights into trust in the B2B environment. They conclude that customer impact, satisfaction and re-use intentions are related to the size of the firm, cost and intensity of services and only marginally impacted by geographical distance. Interestingly, the level of trust of the advisor (including accountants) by the client was not shown to be significant, except for public sector and business association suppliers.

The following papers speak very specifically to the public accountant - SME client relationship. Each of these papers acknowledges the strong level and importance of the relationships public accountants have with their SME clients, as well as the critical impact these relationships have on the overall economy. However, each paper also highlights gaps in expectations between the two parties. The Neu (1991) paper analyses why society trusts public accountants and looks to go beyond the often quoted self-regulatory nature of the profession and the disciplining nature of financial markets. This work emphasises what they refer to as, 
'the circular and self-sustaining nature of professional practices' where the public has no choice but to trust the profession (Neu, 1991, p. 295). This Canadian work speaks very specifically to the auditing profession, but still has implications for the broader public practice accounting arena. The work by Kirby \& King (1997) highlights the mismatch in expectations of public accountants and their SME clients in the UK. It also argues that if public accountants are to fulfil their brief in assisting SMEs develop their management capability, changes need to be made to how they market their services. Two broad change areas were identified, with implications for public accountants and their SME clients:

- Accountant attitudes to raising the awareness of SME clients to issues in their businesses

- Perceptions of accountants by SMEs and the role they can play in improving business performance.

The report by Leung, Raar and Tangey (2008) is of particular importance as it speaks directly to the Australian public accountant - SME client experience. The accountants surveyed reported that the major growth areas in their businesses were in traditional accounting areas (tax and superannuation). However, SME clients were more concerned with the volume and complexity of government regulation as it applied to their businesses. They seemed concerned that they may not be able to keep up with new regulations as well as with duplication of reporting requirements across governments. This work also concluded a need for a stronger role for accountants and their national bodies, in monitoring the broader business services market for threats and opportunities.

The role of the public accountant was also explored and shown to include two broad components (Berry et al., 2006; CPA-Australia, 2014b; ICAA, 2013; IPA, 2014c):

- Conformance advice component - statutory/compliance matters such as taxation

- Performance advice component - non-compliance consulting activities relating to business improvement and growth

Further recent trends within the accountancy sector, outsourcing and offshoring in particular (Noroozi \& Addison, 2008), present opportunities for an increase in the provision of performance related advice by public accountants (Kirby \& King, 1997). The literature acknowledges public accountants as the most prevalent advisors to SMEs, but this in itself does not n e c e s s a rily equate to the trusted advisor (Bennett \& Robson, 2005; Berry et al., 2006; DEWRSB, 1996; Jay \& Schaper, 2003; Kirby \& King, 1997; Leung et al., 2008). The distinction between prevalent and trusted advisor is important and, according to Blackburn et al. (2010) there exists an expectation gap between accountants and their clients and that this gap relates to whether the accountant provides broader business advice (refer to the Performance advice component above). That is, according to Blackburn et al. (2010), the provision of such additional services is a requirement for an accountant to be viewed, "as a business expert, a 'trusted partner', and a confidante who has empathy and provides a personal relationship to the owner-manager" (Blackburn et al., 2010, p. 1). Few studies provide firm empirical guidance on trust determinants within the Australian public accountant - SME client space (Blackburn et al., 2010). The literature reviewed also confirms that the advice provided is primarily of a 
statutory or compliance nature (Berry et al., 2006; Kirby \& King, 1997), with public accountants generally not considered for broad-based management issues. This is at odds with the conformance/performance components detailed in the previous paragraphs. There was acceptance of the benefit of advisory work to overall SME performance (Berry et al., 2006; Dyer \& Ross, 2007). This further supports the opportunity for public accountants to explore broadening of their service offerings to include both conformance and performance components. This conformance versus performance question is further highlighted in the expectations gap identified by several authors (Kirby \& King, 1997; Leung et al., 2008). These papers have identified issues relating to accountants' attitudes towards raising awareness of SME clients to business issues and perceptions by SMEs of the improvement role which accountants can play, as well as differing views on key economic issues and trends. The distinction between conformance and performance service offerings by public accountants was also brought to light in this review. Most importantly, the Blackburn et al. (2010) paper identified the provision of performance advice (or non-compliance business advisory services) as a potentially important determinant of trust, to address the identified expectations gap, within the public accountant - SME client relationship. Blackburn et al. (2010) suggest the following potential trust determinants; that trust is built via an on-going relationship, principally through the provision of conformance or compliance services, that it is built up over time through social rapport. The importance of empathy is also highlighted as vital to the success of the relationship and the provision of performance (or non-compliance) business advisory services (Blackburn et al., 2010).

\section{Trust Definition for Proposed Conceptual Model}

The above review of broader trust definitions and trust models as they relate to business and professional service relationships has highlighted the importance of the following potential elements to trust within the Australian public accountant - SME client relationship:

- Confidence (Dyer \& Chu, 2011)

- Acceptance of vulnerability (Blois, 1999; Dyer \& Chu, 2011)

- Person and offer-related variables (Coulter \& Coulter, 2002)

- Conformance and performance advice (or compliance and non-compliance advice) (Berry et al., 2006)

A working definition of trust is now proposed to describe trust within the Australian public accountant - SME client relationship. It draws from the work described in General Trust Definitions above, Business-to-Business Trust, and from Trust in the Public Accountant SME Client Relationship. It is believed that this definition speaks to the major elements of broader trust (Blois, 1999), B2B trust (Coulter \& Coulter, 2002; J. H. Dyer \& Chu, 2011) and professional services trust globally (Berry et al., 2006) as well as within Australia (Blackburn et al., 2010). In doing so, it provides a sound basis for further investigation of the conceptual model to describe the determinants of trust within the Australian public accountant - SME client relationship:

The SME client's confidence that the public accountant will act proactively in their interests and not exploit their vulnerabilities. 
This paper has investigated the topic of trust, to develop an understanding of the scope and scale of trust definitions across a range of disciplines. It then moved on to focus on definitions of trust within the business setting. Scholarly works relating to trust in a business to business setting were reviewed to provide an understanding of business trust, its antecedents or determinants. Finally, the review focused very specifically on trust within the professional services space, particularly as it related to the public accountant - SME client relationship. The most significant and consistent finding in relation to trust in this environment related to the importance of moving beyond conformance-related services to performance-related services. Additionally, the work by Saunders et al. (2004) and Blackburn et al. (2010) identifies that the area of trust remains underresearched from both business to business relationships generally and Australian public accountant - SME client relationships specifically. As a result of this and the above, the proposed conceptual model has been developed to reflect the current body of scholarly work in this space.

\section{Propositions \& Proposed Conceptual Model:}

As a result of the findings from the prior research in this area, a set of propositions and proposed conceptual model has been developed in an attempt to describe the antecedents of trust in the Australian public accountant - SME client relationship. The following propositions and proposed conceptual model develop the Generic B2B Trust Model (refer to Figure 1.) to relate more particularly to the provision of professional services and specifically to the Australian public practice - SME client relationship.

\section{Propositions}

The following propositions are presented for the investigation of the determinants of trust in the SME - public accountant relationship. These have been developed from the review of the various scholarly papers and particularly the seminal Dyer \& Chu (2011) paper and the Australia-specific Blackburn et al. (2010) paper detailed above. The independent variables chosen relate to the relationship or person-related and offer-related characteristics detailed by many of the models in the prior literature (refer to Figure 1.). The Blackburn et al. (2010) paper, which speaks specifically to trust within the Australian public accountant - SME client arena, highlights the role of trust, relationships and professional ethics in the provision of business advice, beyond traditional statutory/compliance matters. The Dyer \& Chu (2011) paper, which investigated the issue of trust within the broader B2B environment across supplier-automaker relationships in the US, Japan and Korea, and found that trust is significantly correlated with activities which promote relationship continuity. The Norwegian Gooderham et al. (2004) study concluded that the quality, rather than longevity, of the relationship was the major antecedent of the degree to which SME clients used their accountants as broader business advisors. The Kirby and King (1997) (UK) paper highlighted the mismatch in expectations, or expectations gap with respect to the provision of broader advisory services. Bennett and Robson (2005), in another UK study, identified that client satisfaction, impact and re-use intentions as important to business advisor - SME-client relationships. Although there is not a strong consistency in findings across these relevant studies, they do provide some common themes. Additionally, this lack of consistency further justifies the need for additional clarity in this area. The distillation of the findings of the above papers has resulted in the following propositions as possible antecedents, 
or determinants, of trust within the Australian public practice - SME client relationship space. Consistent with previous broader findings, the independent variables, or propositions, are separated into person-related and offer-related characteristics.

\section{Relationship or Person-Related Characteristics:}

Length of Relationship - It is proposed that the longer the duration of the commercial relationship, the higher the SME's trust in the public accountant, per Dyer \& Chu (2011); Gooderham et al. (2004). ( $\mathrm{P}_{1}$. LENGTH)

Face-to-Face Contact - Consistent with the work by Blackburn et al. (2010) and (Dyer \& Chu, 2011), it is proposed that the greater the face-to-face interaction between the public accountant and the SME, the higher the SME's trust in the public accountant. $\left(\mathrm{P}_{2}\right.$. FACE)

Degree of Engagement - The broader the engagement (beyond the normal commercial client/professional services organisation engagement) between the public practice firm and the SME, the higher the SME's trust in their public accountant (Blackburn et al., 2010; Kirby \& King, 1997). ( $\mathrm{P}_{3}$ - ENGAGEMENT).

\section{Offer-Related Characteristics:}

Breadth of Assistance - The greater the assistance provided by the public accountant, the higher the SME's trust in the public accountant (Blackburn et al., 2010; Gooderham et al., 2004). This speaks to the breadth of compliance/conformance-related offerings provided by the public accountant to their SME client. $\left(\mathrm{P}_{4}-\right.$ ASSISTANCE)

Advisory Services Offered - The more non-compliance related assistance provided by the public accountant, the higher the SME's trust in the public accountant (Blackburn et al., 2010; Kirby \& King, 1997). This business advice moves beyond the core compliance/conformancerelated offerings. $\left(\mathrm{P}_{5}-\mathrm{ADVISORY}\right)$

Accreditation Body - The public accountant's accreditation body, Institute of Public Accountants (IPA), CPA Australia (CPA) or Chartered Accountants Australia and New Zealand (CAANZ) impacts the level of trust in their public accountant (Blackburn et al., 2010). ( $\mathrm{P}_{6}$ ACCREDITATION)

Size - The larger the public practice firm, the higher the SME's trust in their public accountant (Dyer \& Chu, 2011). $\left(\mathrm{P}_{7}-\mathrm{SIZE}\right)$

\section{Proposed Conceptual Model}

To date, no testable conceptual model has been developed to describe the antecedents of trust in the Australian public accountant - SME client relationship. The work by Blackburn et al. (2010) speaks to the broader areas of the role of trust, relationships and ethics in the provision of business advice by public accountants to their SME clients. In doing so it provides invaluable 
guidance via a conceptual framework for business advice in this context as well as potential trust determinants; however it does not provide a testable model nor test for these determinants. The work on trust by Dyer \& Chu (2011) provides useful insights and potential trust determinants, but in a broader B2B and international (USA, Japan and Korea) context. The Kirby \& King (1997) work does speak specifically to the public accountant - SME relationship (in the UK), but focuses on the expectations gap (conformance advice versus performance advice) and does not provide a model for trust. The Bennett \& Robson (2005), another UK paper, speaks to the broader advisor - SME client relationship, which includes friends/relatives, bankers, lawyers, customers, consultants and public accountants. This paper also focuses on the relationship between the types of advisor used and the level of impact and satisfaction received by the SME client. It provides useful insights into the potential determinants of trust, but does not focus here, nor test for these specifically. The Gooderham et al. (2004) article speaks to the topic of accountants as a source of business advice for SMEs, in the Norwegian experience. As is the case with the other papers reviewed, it provides excellent insights into possible trust determinants, but does not particularly focus in this area. Drawing the above variables together, the following conceptual model (Figure 2. below) is suggested to assess and determine the determinants of trust in the public accountant - SME relationship in Australia. 
Figure 2. Proposed Conceptual Model - Determinants of Trust in the Australian Public Accountant - SME Client Relationship

TRUST $=a+b_{1}$ LENGTH $+b_{2}$ FACE $+b_{3}$ ENGAGEMENT $+b_{4}$ ASSISTANCE $+b_{5}$ ADVISORY $+b_{6}$ ACCREDITATION $+b_{7}$ SIZE

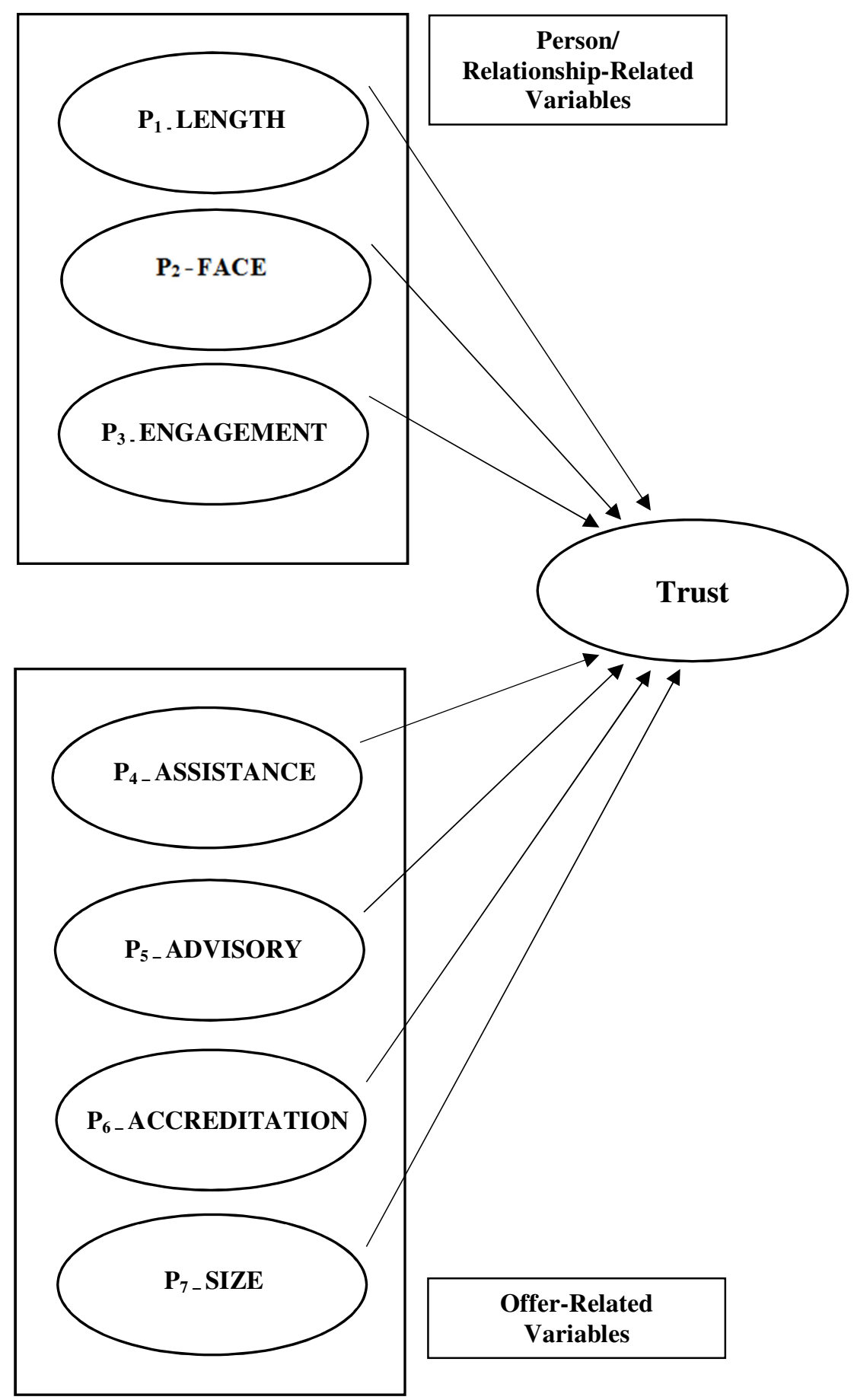




\section{Conclusion}

This conceptual model is presented in an attempt to better understand the value provided by Australia's public accountants to their SME client base. It explores the oft-quoted adage of the public accountant as the SME clients' trusted partner (Bennett \& Robson, 2005; Berry, Sweeting \& Goto, 2006; Jay \& Schaper, 2003; Kirby \& King, 1997; Leung, Raar \& Tangey, 2008). In doing so, this model presents potential antecedents or determinants of trust in this relationship. Specific empirical studies are therefore necessary to test the conceptual model. The outcome of which may contribute to a stronger understanding of the trends and challenges faced by the public practice accountancy sector and their SME client base. Such empirical studies may shed further light on the degree to which relationship-related variables (duration of relationship, degree of contact and engagement) and offer-related variables (breadth of assistance provided, degree to which advisory services are utilised, the public accountant's accreditation body and firm size) contribute to the development of trust in the relationship. Other practical outcomes of this work have been the development of a working definition of trust as it relates to the Australian public practice - SME client relationship;

\section{The SME client's confidence that the public accountant will act proactively in their interests and not exploit their vulnerabilities.}

as well as a new definition for public accountants, which better suits the current and anticipated challenges faced by accountants and their clients;

\section{Australia's public accountants provide clients with financial conformance and performance services. Financial conformance services speak to compliance-related activities, whereas financial performance services speak to broader business advisory activities, aimed at business improvement and growth.}

The conceptual model presented is designed as a platform to encourage future research in relation to trust as it relates to the Australian public accountant - SME client experience. In doing so there are three potential broad audiences for the outcomes of such work; practitioners, SMEs and academics. Practitioners, in the first instance, cover Australian public accountants themselves through to the various officially recognised bodies (IPA, CPA and CAANZ) which represent the industry. It may provide these practitioners with insights into how better to serve and develop the relationship with their client base. Findings from future empirical studies may also inform practitioners beyond public accountants, including other professional services organisations, for example; law firms, architects, management consultants, financial advisors and engineering consultancy firms, amongst others. Another beneficiary of any identified relationships is likely to be the SME clients of Australia's public accountants. There may be broader benefits to SMEs through a better understanding of the benefits which can accrue from a more effective relationship with their public accountant. There may be learnings for academia within and beyond Australia. Researchers may be provided with insights which will provide the opportunity for further refinement and development of the relational model and development of research in this area. Findings may also have implications for the development and delivery of academic programmes in the professional accounting space, as well as required professional accreditation programmes and ongoing education. The proposed conceptual model and 
propositions seek to provide further clarity around the determinants of trust in the Australian public accountant - SME client relationship and, in doing so, position the profession to meet current and projected challenges.

\section{References:}

ABS. 2005. A statistical view of counts of businesses in Australia. (8162.0). Australian Bureau of Statistics.

ACCA. 2013. Accountants for small business. The Association of Chartered Certified Accountants

ACCI. 2014. ACCI small business survey. Australian Chamber of Commerce \& Industry.

AICD. 2013. Key issues to be on top of in 2014. Retrieved from www.companydirectors.com.au

APESB. 2008. Discussion paper - issues impacting the accounting industry from outsourcing. Retrieved from Australia: www.apesb.org.au

Australian Accountants Directory. 2014. About accountants. Retrieved from www.australianaccountantsdirectory.com.au

Bennett, R. J., \& Robson, P. J. A. 2005. The advisor-SME client relationship: impact, satisfaction and commitment. Small Business Economics, 25, 255-271. http://dx.doi.org/10.1007/s11187-003-6459-3

Berry, A. J., Sweeting, R., \& Goto, J. 2006. The effect of business advisers on the performance of SMEs. Journal of Small Business and Enterprise Development, 13.(1.), 33-47.

Blackburn, R. A., Carey, P., \& Tanewski, G. 2010. The role of trust, relationships and professional ethics in the supply of external business advice by accountants to SMEs. Paper presented at the Australian Centre for Financial Studies-Finsia Banking and Finance Conference. http://dx.doi.org/10.2139/ssrn.1592342

Blois, K. J. 1999. Trust in business to business relationships: an evaluation of its status. Journal of Management Studies, 36(2), 197-215. http://dx.doi.org/10.1111/1467-6486.00133

Blomqvist, K. 1997. The many faces of trust. Scandinavian journal of management, 13(3), 271286. http://dx.doi.org/10.1016/S0956-5221(97)84644-1

Chia, S. 2014. Accounting services in Australia. Retrieved from Australia:

Chumpitaz Caceres, R., \& Paparoidamis, N. G. 2007. Service quality, relationship satisfaction, trust, commitment and business-to-business loyalty. European journal of marketing, 41(7/8), 836-867.

Clarke, M. 2011. Accountants emerge as businesses' most trusted advisors. Retrieved from www.freshbusinessthinking.com website:

Coulter, K. S., \& Coulter, R. A. 2002. Determinants of trust in a service provider: the moderating role of length of relationship. Journal of Services Marketing, 16(1), 35-50.

CPA-Australia. 2014. About us. Retrieved from www.cpaaustralia.com.au

CPA-Australia, \& CGA-Canada. 2010. Report of the forum on SME Issues - unlocking the potential of the SME sector. Retrieved from Australia \& Canada:

Creighton, A. 2012. SMEs crucial to economic strength. The Australian. Retrieved from www.theaustralian.com.au website:

Culkin, N., \& Smith, D. 2000. An emotional business: a guide to understanding the motivations of small business decision takers. Qualitative Market Research: An International Journal, 3 (3), 145-157. 
Department of Innovation, I., Science and Research. 2011. Key statistics, Australian small business. Commonwealth of Australia.

DEWRSB. 1996. A portait of Australian of business: Results of the 1996 business longitudinal survey. Canberra: Commonwealth of Australia.

Dyer, J. H., \& Chu, W. 2011. 2010 DECADE AWARD WINNING ARTICLE: The determinants of trust in supplier-automaker relationships in the US, Japan, and Korea. Journal of International Business Studies, 42(1), 10-27. doi:10.2307/25790101

Dyer, L. M., \& Ross, C. A. 2007. Advising the small business client. International Small Business Journal, 25(2), 130-151. http://dx.doi.org/10.1177/0266242607074517

Ferguson, L. 2012. Gaining (from) your clients' trust - How CPAs can shift from service provider to essential business adviser. Journal of Accountancy. Retrieved from www.journalofaccountancy.com website:

Gooderham, P. N., Tobiassen, A., Døving, E., \& Nordhaug, O. 2004. Accountants as sources of business advice for small firms. International Small Business Journal, 22(1), 5-22.

Griffith, G., \& Wilkinson, J. 2012. Small business in NSW: Statistical snapshot and recent developments. Sydney: Parliament NSW.

ICAANZ. 2013. What is a Chartered Accountant and what makes them different? Retrieved from www.charteredaccountants.com.au

IPA. 2014a. IPA mission \& vision. Retrieved from www.publicaccountants.org.au

IPA. 2014b. What is a public accountant? Retrieved from www.publicaccountants.org.au

Jay, L., \& Schaper, M. 2003. Which advisors do micro-firms use? Some Australian evidence. Journal of Small Business and Enterprise Development, 10(2), 136-143. http://dx.doi.org/10.1108/14626000310473166

Khadem, N. 2012. Accounting 100: The fight for the top. Retrieved from www.brw.com.au website:

Khadem, N. 2013. Kill or be killed: BRW top 100 accounting firms 2013. Retrieved from www.brw.com.au

Kirby, D. A., \& King, S. H. 1997. Accountants and small firm development: Filling the expectation gap. The Service Industries Journal, 17(2), 294-304. http://dx.doi.org/10.1080/02642069700000017

Leung, P., Raar, J., \& Tangey, G. 2008. Accounting services and SMEs: An Australian study. The Association of Chartered Certified Accountants.

Lian, P. C., \& Laing, A. W. 2007. Relationships in the purchasing of business to business professional services: The role of personal relationships. Industrial Marketing Management, 36(6), 709-718. http://dx.doi.org/10.1016/j.indmarman.2006.05.004

Neu, D. 1991. Trust, impression management and the public accounting profession. Critical Perspectives on Accounting, 2(3), 295-313. http://dx.doi.org/10.1016/1045-2354(91)90015-6

Noroozi, A., \& Addison, G. 2008. [Submission on the discussion paper by the Australian Taxation Office on outsourcing and offshoring].

Olsen, D. 2010. Accountants most trusted advisers to small business. Dynamic Business - News, Opinion, Debate. Retrieved from www.dynamicbusiness.com.au website:

Robson, P., \& Bennett, R. J. 2000. The use and impact of business advice by SMEs in Britain: an empirical assessment using logit and ordered logit models. Applied Economics, 32(13), 1675-1688. 
Rosenbaum, M. S., Massiah, C., \& Jackson Jr, D. W. 2006. An investigation of trust, satisfaction, and commitment on repurchase intentions in professional services. Services Marketing Quarterly, 27(3), 115-135. http://dx.doi.org/10.1300/J396v27n03_07

RSM Bird Cameron. 2012. thinkBIG: Connecting you to the issues, challenges and opportunities facing SMEs. Retrieved from www.rsm.global:

Saunders, C., Wu, Y. A., Li, Y., \& Weisfeld, S. 2004. Interorganizational trust in B2B relationships. Paper presented at the Proceedings of the 6th international conference on Electronic commerce.

Schoorman, D., Mayer, R. C., \& Davis, J. H. 1996. Including versus excluding ability from the definition of trust. Academy of management review, 21(2), 339-340.

Seal, W., \& Vincent-Jones, P. 1997. Accounting and trust in the enabling of long-term relations. Accounting, auditing \& accountability Journal, 10(3), 406-431. http://dx.doi.org/10.1108/09513579710178133

Sharif, K. J., Kalafatis, S. P., \& Samouel, P. 2005. Cognitive and behavioural determinants of trust in small and medium-sized enterprises. Journal of Small Business and Enterprise Development, 12(3), 409-421. http://dx.doi.org/10.1108/14626000510612312

Wang, C., Walker, E., \& Redmond, J. 2007. Explaining the lack of strategic planning in SMEs: The importance of owner motivation. International Journal of Organisational Behaviour, $12(1), 1-16$. 